\title{
Existential Onto-phenomenology of M. Heidegger and Theological Representation of Temporality
}

\author{
Alexander Glazkov ${ }^{1, *}$ \\ ${ }^{1}$ Department of Philosophy, Astrakhan State University, Astrakhan, Russia \\ *Corresponding author. Email: alpglazkov@yandex.ru
}

\begin{abstract}
Existence, from the point of view of M. Heidegger, is a conscious human being, which is based on temporality. Existentials are the modes of temporality that establish the structure of its existence. The structure of existence is aimed at a meaningful perception of oneself and reality. In self-consciousness, when the existent subject is Dasein, cognizes himself, the leading intelligibility that guides his understanding and self-consciousness is temporality. This temporality, being perceived in the closest way only from the inner-world being, as expressed and proved by M. Heidegger, is genuine, since it deals with the real being, but at the same time incomplete. For a complete understanding, a theoretical level of knowledge is required, which includes ideals that have the character of timelessness. Timelessness presupposes the status of theology for ideals. Theology, focused on holistic and perfect, and therefore eternal ideals, opens up an opportunity for overcoming in understanding the limit of time. As a result, the understanding of being as temporality acquires a new eschatological meaning. There is a theological renewal of existence. Everything that is temporary is comprehended through timeless ideals. The existential perception of temporality loses the tragic character of the finitude of being and can already be considered as an opportunity to overcome finitude and enter into another being.
\end{abstract}

Keywords: Existence, Temporality, Dasein, M. Heidegger, Onto-phenomenology, Eschatology, Theology.

\section{INTRODUCTION}

"Time", "temporality" - these words, perhaps, are the closest to us in our everyday life. Through the concept of "time" we measure the movement, give meaning to this or that action, fix the change. The word "temporality" carries with it various semantic connotations of human life: we have "little time", "time is passing quickly," "time is dragging on," "it's time to do something", etc. In the designation of the temporality of our being, the meaningfulness of our life is included. What is seen as a simple physical movement or transformation, at the mental level through various expressions of temporality, is realized, synthesized into a single meaningful whole. As Mikhailov notes: "Time is a relative or correlative category, and therefore it does not exist in itself, but is present only in correlation. This is a paradox that cannot be resolved by philosophical means. Physical time exists beyond any doubt; the time of everyday life also does not require any special proof for its recognition". [1]

"Time", "temporality"- these designations of the actual changeability of human existence and the world that belongs to him, which they affect and enters into his worldview, belong to the level of awareness (and comprehension) of reality, which thus becomes human, is perceived as the human world. Therefore, if we begin to clarify the mechanism of the formation of human selfawareness, temporality as a specific reality of human existence, will inevitably be in the center of our attention.

Human life is temporary, and the understanding of time, temporality is included in the semantic basis of realizing reality. In this regard, it is of interest to consider the mechanism of the birth of this awareness, to clarify the issue of the variability of such awareness within this temporality, which is one of the most important factors that set the horizon of understanding. 
The idea of $M$. Heidegger, presented in his famous work "Being and Time", that the meaning of being of a self-conscious subject (Dasein) lies in temporality, has a powerful heuristic potential. As M. Heidegger writes: "Only because Da-sein is determined as temporality does it make possible for itself the authentic potentiality-of-being-a-whole of anticipatory resoluteness which we characterized. Temporality reveals itself as the meaning of authentic care". [2]

The fundamental ontology, developed at the time by this German thinker, is of great methodological importance for understanding how temporality is present in human consciousness of oneself and the world. The assumption that temporality underlies all our acts of cognition is very productive when considering the ontological basis of the cognitive process. Heidegger connects the possibility of understanding being and temporality: "Because temporality constitutes the basic constitution of the being we call the Dasein, to which entity the understanding of being belongs as determination of its existence, and because time constitutes the original self-projection pure and simple, being is already always unveiled - hence being are either disclosed or uncovered - in every factical Dasein, since it exists". [3]

At the same time, it seems that the path of fundamental ontology is insufficient to clarify the fullness of the meaning that temporality has in the understanding perception of a person. Within the framework of this article, in the context of the fundamental ontology of Martin Heidegger, the role of the theoretical concept of time and its meaning in the process of personality self-awareness is revealed. Thephilosophical comprehending of the understanding of temporality in self-consciousness is considered as a form of theoretical representation. Theology is taken as one of the options for the ultimate theoreticalness of philosophy, which is considered as a branch of philosophy. Philosophy begins its path in many ways as theology, therefore the theological nature of philosophy can be considered as its natural characteristic feature, at least for its individual types, which in general can be called metaphysics. We proceed from the fact that the existentials of temporality, which were developed within the framework of the fundamental phenomenology of M. Heidegger, do not conflict with the categories related to the theoretical concept of temporality, and they all together complement each other. Thanks to this synthesis, the completeness of the philosophical picture of the world is achieved.

\section{EXISTENCE AND TEMPORALITY}

It is known that M. Heidegger advocated overcoming metaphysics, and saw this overcoming in the development of existential understanding. The existential, at its core, is meaningful perception. Sensory perception of reality passes through it and at the same time it is comprehended. Through existentiality, the tenses of Dasein and, accordingly, the tenses of being as a whole are revealed. According to Heidegger, as N.I. Ishchenko notes, "temporality cannot" exist", since there is another ("present") thing and how the person himself exists, whose being it shines through, therefore it has its own way of being. Heidegger calls it "temporalizing" In other words, temporality does not exist, but it temporalizes". [4]

Temporalizing Dasein is a consequence of its inclusion in being, which temporalizes. This cotemporality of Dasein and Sein allows us to understand being as temporality. According to A.G. Chernyakov: "Time turns out to be the horizon from which being as such - being in its difference from beings - is generally comprehensible. In a way, time is the ontological difference. However, strictly speaking, time is not, time is not being among things, but is the fundamental structure of being Dasein, being that understands the being of comprehension". [5] Therefore, the tense Dasein can also be considered as the existential basis of self-awareness. At the same time, the existential level of understanding of temporality is only the initial stage of self-awareness, which Heidegger associates with the inner-world being as an assistant funded in care. As A.G. Chernyakov: "Dasein should already be ahead of itself in order for the presence of "for-what" and "in-order-to" to become possible. The latter is not an object, therefore, what the definition of care as "already-ahead-of-itself" means, is not a protention - a special way of being given. "Ahead-of-yourself" is not a special intentionality, a special relationship with an object or with some of its moment, aspect or side; it is just a vector of throwing, an initial opening (of oneself) in the direction of that from which something-forwhat is done every time, acquiring the appearance of the present state of affairs". [6] Thus, we can say that existentiality is the primary step of awareness, associated with the closest arrangement of oneself in existence. We must admit the possibility of another level of self-awareness, without which it would be impossible to talk about the achievement of the completeness of the process of consciousness. We are talking about the emergence 
and inclusion in the process of awareness of the idea of temporality itself. This idea of temporality is born from the synthesis of the perception of temporality and the concept of temporality.

The concept of temporality arises in the mind and is a category of time. The peculiarity of the category of time lies in its timelessness, therefore ideality appears. The very act of self-awareness, which occurs together with the act of conscious perception, is impossible without a timeless ideal expressed in a verbal way. I. Kant in his famous work "Critique of Pure Reason" noted that the ideals "provide an indispensable standard for reason, which needs the concept of that which is entirely complete in its kind, in order to assess and measure the degree and the defects of what is incomplete". [7]

Imperfect can be called something that is subject to change, that is, temporarily. The temporal is not perfect, but in order for us to realize this, we need an ideal, which, by its definition is perfection, and in this status is out time. Thus, the temporal is realized through the timeless, the timeless has the status of eternity. Functionally, in the process of activity of consciousness, temporality turns out to be associated with eternity. As V.V. Bibikhin notes: "Our time is a product of eternity in that simple and immediate sense that ... at first we ourselves somehow ... looked into eternity as an all-embracing identity or unity, and then a grid of time was instantly projected from it onto all the events of the world. ... at first we have already seen eternity, so that we can simply see time, - we ourselves had to have some kind of eternity in our eyes ..." [8]

\section{EXISTENCE AND IDEALS OF REASON}

The status of the timelessness of the ideal is theological in its position in theoretical case. The ideal can be developed and assimilated by consciousness in various ways. The ideal can correspond to reality and be actually perfect, or it can be false, built on imagination, but without it the process of awareness and self-awareness will not be realized. The ideal is not taken from experience, since ideals do not meet in life. The ideal is found, it is revealed in insight, it is taken on faith, people believe in ideals, they are confident in them, they come to them as a result of reflection. The ideal is sought by the heart, selected by the mind, its options are logically sorted out, until the moment when everything falls into place. Within the framework of the accepted ideal, everything falls into place and understanding is born. To express ideals requires literature, speech. In the unreasonable forms of life, there is no level claiming the status of eternity. Therefore, unreasonableness is wordless.

Reason relies in its judgments on those criteria that for it has the status of ideal and eternal. In this regard, it should be noted that the level of ideals is natural for reason and is necessarily present in the structure of self-consciousness.

The peculiarity of finding the ideal in the mind is that it logically gets over and is selected by the mind until the moment when everything falls into place. Ideals are that within which everything temporary takes on meaning and finds itself in its place in the stream of change.

The ideal is affirmed in the mind by faith, which also testifies to its theological nature. Faith, therefore, is also an element participating in the concept of temporality. Thanks to faith, the ideal is included in the mind and participates in intelligent activity, in the awareness of the temporary, which is perceived in a sensual way and existentially perceived. Through faith, consciousness, as it were, leaves the stream of time, and due to this, a priori fundamental assumptions are formed. Faith is a priori, and it adjusts consciousness, disposes and determines the temporal, in fact, structure of existentials.

The existential understanding of temporality presupposes the finitude of Dasein, its being-todeath. The inevitability of the end creates a mood of anxiety, fear. Temporality is finitude. Time inevitably moves everything that exists in this world to destruction. Realization of this gives rise to fear of the inevitable end of time for everything and everyone, which will come sooner or later. This is a kind, as V.V. Bibikhin - "the apophaticity of time". [9] That is temporary, everything is relative and will eventually disappear. Nothingness, nothing gives rise to temporality, the realization of which inevitably leads us to the thought of disappearance. We can label these sentiments as "eschatic". If you focus exclusively on the existential level of understanding of being, then such moods can acquire an absolute character for Dasein. The theoretical level of rational understanding, or rather its theology, focused on holistic and perfect, and therefore eternal ideals, opens up the possibility for representations, to some extent, removing the tragedy of the finitude of all temporary existence. The step of the imperfect and temporary towards 
improvement on the basis of the accepted ideal also transforms the mood of existence. Rapprochement with the ideal removes temporality from the mood and leads to eternity. From the position of eternity, everything that temporarily imperfectly inevitably moves towards destruction, but if a turn towards perfection is made, then the theoretical possibility of gaining immortality opens up. Such a turn presupposes moral improvement and requires determination.

\section{ESCHATOLOGICAL TIME OF THEOLOGY}

Overcoming the ultimate - eschatos, creates a new existential disposition of consciousness, which acquires an eschatological character. Eschatology in this case is considered as the certainty of overcoming the limit of this being and entering into a new perfect being. Existentials, in synthesis with theoretical knowledge tuned in an eschatological way, renew the perception of temporality. Eschatological consciousness perceives and understands the world from a different angle. Time is viewed not as a tragic inevitability of the end of one's own life, but as a given opportunity to overcome finitude and enter into another being. Then, in the existential structure of Dasein, care, through which the understanding of being as temporality is gained, acquires a new eschatological meaning. This is an entry into eternity. The concept of entry of eternity into temporality generates a new temporality, which can be designated as kairos. Kairos - in contrast to the tragically perceived time - chronos, can be seen as an auspicious time. This favorable time is different in its existential characteristics. As John (Panteleimon) Manussakis notes: "Against this concept of time as chromos (the passing of time) stands a different understanding of temporality as kairos. If chronological time is seen in a horizontal way, that is, as sequence and duration, kairos could be represented as vertical and dis- continuous. If chromos is measured in seconds, minutes, hours, and years, kairos cannot be measured at all, since it occurs only in the Moment. What is called here "the Moment" - that is, as we will see, the Augenblick or the exaiphnes - is characterized by this dis- continuity through which, according to Heidegger, the world is dis-closed and Dasein is faced with his or her de- cision". [10]

Through the understanding of time as kairos, the eschatological dimension of temporality is established, the true understanding of temporality is revealed thanks to the eschatological eternity.

The future in the existential structure of Dasein care does not always step into its own, authentic for itself and open in understanding future. It may not step into its own future if it adheres to improperness as a mode of existence, and then it will enter an improper future, while its own future may be closed to it. An important question here is the definition of the meaning of one's being, that is, (on-what) the direction of care, as a way of being Dasein, which Dasein chooses. If these are objects of everyday employment, which can have an exclusively relative nature, then it will make the final content of the meaning of its being nothing, that is, ultimately, nonsense.

Worldly everyday life, having seized Dasein at its disposal, will impose its own understanding for Dasein. This kind of improper existence of Dasein is indecisive, withdrawn, expectant and passive. Submitting itself to affairs, value attitudes and preferences of the temporary and finite world, Dasein finds itself, according to Heidegger's ontophenomenology, in a suffering position. Thus, the ultimate from the eschatological point of view, stay has the character of suffering, indecision, alienation from oneself, (one's self-understanding) and one's ability to be.

Freed from the power of the world, overshadowing its understanding by an improper understanding of opinions and interpretations, Dasein acquires the ability to be a self and through this acquires the sharpness and clarity of an understanding look, undistorted by peacefulness. Then his very ability to be opens the intercession into death, as into his own, not connected with anything and with anyone, possibility, that is, his own future.

\section{CONCLUSION}

From the point of view of eschatological theology, the deeds of death, as transient and insignificant, are meaningless from the point of view of achieving eternal life. Since an understanding that contains, by definition, all possible meanings should be aside from nonsense, then a time that carries meaning can be for Dasein only from the future. The future contains the possibility of being or becoming in some way. According to Heidegger, the future makes its own Dasein ontologically possible. The image of the 
future Dasein, his ideal, becomes the key moment for the meaning of care.

According to the eschatological theoretical theology, the basis of the existence of Dasein is the ontological possibility of the transition, transcensus, through the limit of temporality into the reality of the eternity of the eschaton. If temporality is the non-beings, since it is nothing of what is as beings, and being temporalizes, then eternity will be precisely the super-being of the super-beings, which is the source of temporality and carrying existential temporality. The rootedness of meaning in this case does not lie in simply temporary the future, but in eternity.

The future will be positioned in the futureeternity, that is, the eternity to come in the future. Eschatological determination is ontologically different and requires much more than Heidegger's onto-phenomenology suggests. It requires abandoning oneself present and one's present future, and moral correction of oneself for another, eternal future. It is the authenticity of Dasein that is subject to decisive correction in the face of eternity, and only the corrected authenticity can be renewed already in the eternity of life. Uncorrected authenticity is renewed not to eternal life, but, as before, to eternal death. The future that opens to it also depends on the quality of genuine Dasein. One's own Dasein, genuine one's own, still needs to be changed in order to achieve a favorable future. In this change lies the theological renewal of existence.

\section{AUTHORS' CONTRIBUTIONS}

This paper is independently completed by Alexander Glazkov.

\section{REFERENCES}

[1] Mikhailov P.B. "The category of time in Christian metaphysics: Gregory of Nyssa and Maxim the Confessor", $\Sigma \mathrm{XO} \Lambda \mathrm{H}, 2015$, Vol. 9, pp.119-136, p. 120.

[2] Heidegger Martin, "Being and time", translated by Joan Stambaugh, State University of New York Press, Albany, 1996, p.487 p., p.300.

[3] Heidegger Martin, "The basic problems of phenomenology", translated by Albert Hofstadter, Indiana University Press, Bloomington \& Indianapolis, 1988, 396 p., p.318.
[4] Ishchenko N.I. "Martin Heidegger's Dasein Analytics and the Problem of Temporality", Artikult, 2016, Vol.4, pp.73-78, p.75.

[5] Chernyakov A.G. "Ontology of time. Being and time in the philosophy of Aristotle, Husserl and Heidegge'r, St. Petersburg, Higher religious and philosophical school, 2001, 460 p., p.17-18.

[6] Chernyakov A.G. "Ontology of time. Being and time in the philosophy of Aristotle, Husserl and Heidegge'r, St. Petersburg, Higher religious and philosophical school, 2001, 460 p., p.305.

[7] Kant Immanuel, "The critique of pure reason", translated by Paul Guyer, Allen W. Wood, Cambridge University Press, 1998. 785 p. p.552

[8] V.V. Bibikhin "It's time (time-being)", St. Petersburg, Vladimir Dal, 2015, 367p. p.67.

[9] V.V. Bibikhin "It's time (time-being)", St. Petersburg, Vladimir Dal, 2015, 367p. p.178.

[10] Manoussakis, John Panteleimon, "God after metaphysics: a theological aesthetic", Indiana University Press, Bloomington and Indianapolis, 2007, 213 p., p.59. 